\title{
Establishment of the SingHealth Diabetes Registry
}

This article was published in the following Dove Press journal:

Clinical Epidemiology

\author{
Daniel Yan Zheng Lim (D) \\ Sing Yi Chia (D) \\ Hanis Abdul Kadir ${ }^{\prime}$ \\ Nur Nasyitah Mohamed Salim' \\ Yong Mong Bee $\mathbb{D}^{2,3}$
}

'Health Services Research Unit, Singapore General Hospital, Singapore, Singapore; ${ }^{2}$ Department of Endocrinology, Singapore General Hospital, Singapore, Singapore;

${ }^{3}$ SingHealth Duke-NUS Diabetes Centre, Singapore Health Services, Singapore, Singapore
Correspondence: Yong Mong Bee SingHealth Duke-NUS Diabetes Centre, 20 College Road, Academia, Singapore, 169856, Singapore

Tel +6563213753

Fax +6562273576

Email bee.yong.mong@singhealth.com.sg
Purpose: To describe the inception and structure of the SingHealth Diabetes Registry (SDR) as well as the methodology used to set up the registry. The SDR was established to facilitate systematic and standardized data collection for diabetes mellitus within Singapore Health Services (SingHealth), which is an Academic Medical Center (AMC) and Singapore's largest group of healthcare institutions. The diabetes casemix and outcome variables within the registry cohort are also provided.

Materials and Methods: The SDR is built from SingHealth's electronic medical records (EMR) and clinical databases. It covers all individuals aged 18 and above with diabetes mellitus, excluding those with pre-diabetes. Cases are annually ascertained using criteria that include diagnosis codes, prescription records and laboratory test records. Data collection of casemix and outcome variables for the period 2013 to 2019 is complete.

Results: The SDR stands at 208,102 ascertained individuals, distributed across 8 healthcare sites within the AMC. The cohort is broadly reflective of the local gender and ethnic compositions but has a high proportion of older individuals with a mean age of $65.8 \pm$ 13.7 years. Majority ( $>99 \%$ ) have type 2 diabetes mellitus, with multiple other comorbidities (hypertension $84.1 \%$, hyperlipidemia $86.2 \%$, established cardiovascular disease $34.1 \%$ ). At present, majority of individuals are able to meet key process indicators and $52.7 \%$ have a mean $\mathrm{HbA} 1 \mathrm{c}$ of $<7 \%$ ( $53 \mathrm{mmol} / \mathrm{mol})$. Areas of potential improvement include increasing eye and foot screening rates, as well as glycemic control for the $19.5 \%$ of individuals with mean $\mathrm{HbA} 1 \mathrm{c}>8 \%$ (64 $\mathrm{mmol} / \mathrm{mol})$.

Conclusion: The SDR is a large-scale, comprehensive, and representative diabetes registry that incorporates EMR data across the primary and hospital-based care continuum, in a major AMC in Singapore. The SDR has identified areas of improvement in diabetes processes and outcomes. It will support future quality assessment and improvements in diabetes care.

Keywords: diabetes mellitus, electronic data processing, epidemiology

\section{Introduction}

Diabetes is a major and growing health problem worldwide. In Singapore, the prevalence of diabetes among adult Singaporeans aged 18 to 69 years is a high of $8.6 \%$ in $2017 .{ }^{1}$ Diabetes also accounted for $10.4 \%$ of the total burden of disease in the nation, resulting in approximately 57,000 years of life lost to death or ill health. ${ }^{2}$ There is an urgent need to improve diabetes outcomes in order to reduce the burden on patients and the health system.

High-quality, real-world data are necessary for health systems to improve diabetes care. Measurement of diabetes-related morbidity, comorbidity, outcomes of care, and causes for variation can allow targeting of appropriate health services improvements to high-risk populations and areas where service gaps exist. ${ }^{3,4}$ Systematic monitoring of treatment and outcomes over time also allows objective 
assessment of the quality of diabetes care and facilitates broader healthcare decision-making. Real-world clinical practices can be audited and benchmarked at the individual level, institution level and population level. ${ }^{5,6}$

Diabetes registries address the above needs through systematic and standardized data collection. Internationally, the only standard promulgated is defined by the International Consortium on Health Outcome Measurement (ICHOM). ${ }^{7}$ It specifies a set of casemix variables and outcome measures that can be used in setting up a diabetes registry. The standardized set allows comparison between different registries. However, each registry must determine how the relevant fields can be systematically populated from available data. Various diabetes registries have been set up internationally, with varying degrees of completeness and success. ${ }^{8}$

In Singapore, other diabetes registries include the National Healthcare Group Diabetes Registry (NHGDR), ${ }^{9}$ and the National Diabetes Database. ${ }^{10}$ The NHGDR has published data from a cohort spanning the years 2005 to 2008 comprising 170,513 individuals identified from electronic medical records, but more recent epidemiology has not been published. The National Diabetes Database was established in 2016 by the Ministry of Health as part of the local "War on Diabetes" to support healthcare policy, but its data is not publicly available for use in research or quality improvement. We hoped to expand on local efforts to capture up-to-date information on diabetes in the general population, taking into account the major changes in diabetes care over the past decade (viz new diagnostic criteria based on HbA1c, ${ }^{11,12}$ new drug class such as sodium-glucose cotransporter 2 (SGLT2) inhibitors, changes in type 2 diabetes treatment algorithms), ${ }^{13}$ and improving availability of such data.

Our institution, Singapore Health Services (SingHealth), is an Academic Medical Centre (AMC) and is the largest of the three healthcare clusters in Singapore. It consists of four acute hospitals, five national specialty centers, three community hospitals and eight primary care clinics (SingHealth Polyclinics), ${ }^{14}$ which cumulatively provide health services to approximately $50 \%$ of the population of Singapore. SingHealth has a comprehensive electronic medical records (EMR) system that spans the continuum of primary to quaternary care, with inpatient and outpatient data. The SingHealth Diabetes Registry (SDR) was populated from EMR systems and integrated data from existing clinical databases within the AMC. The aim was to provide a comprehensive overview of individuals with diabetes from available digital systems, to support clinical audit and quality improvement projects. This paper describes the methodology used to set up the SDR and provides an overview of the diabetes casemix within the registry cohort.

\section{Materials and Methods Administration and Governance of the SingHealth Diabetes Registry}

The SDR covers all Singapore Citizens and Singapore Permanent Residents with diabetes mellitus, aged at least 18 years, that had healthcare encounters in any SingHealth institution. It was initiated in the year 2015 and has been populated with data backwards and forwards to cover the period 2013 to 2019. Individuals with pre-diabetes are excluded from this registry.

The establishment of the SDR was given overall approval by the SingHealth Centralised Institutional Review Board (CIRB). For this registry, participation requires no data collection beyond that of routine clinical care and poses no additional risks to clinical providers or their patients. Identifying information is only used to join data from different databases and is masked from all researchers querying the data. Hence, a waiver of written informed consent was granted by the CIRB. This study was also endorsed by the SDR Disease Registry Committee. The registry operates in compliance with Singapore's Personal Data Protection Act and the Human Biomedical Research Act, as well as other ethical guidelines based on the Declaration of Helsinki. ${ }^{15-17}$

\section{Data Pipeline of the SingHealth Diabetes Registry}

In Singapore, information technology for the public healthcare sector is centrally managed by the Integrated Health Information Systems (IHiS) agency. IHiS administers the SingHealth-IHiS Electronic Health INtelligence System (eHINTS), which is an enterprise data repository that integrates information from multiple healthcare transactional systems including clinical, administrative, and other ancillary systems. This includes the SingHealth EMR system, which has been the Sunrise Clinical Manager (SCM) EMR from Allscripts Healthcare Solutions since 1999.

Within SingHealth, other large disease-specific databases are maintained by tertiary medical institutes. We 
acquired and merged data regarding cardiovascular comorbidity from the Singapore Cardiac Data Bank (SCDB), a national cardiac disease and outcomes registry hosted by the National Heart Center Singapore. ${ }^{18,19}$ The same process was done for diabetic retinopathy screening data from the Singapore Integrated Diabetic Retinopathy Program (SiDRP) hosted by the Singapore National Eye Center. ${ }^{20}$

Ascertained individuals with diabetes are drawn into the SDR on an annual basis at the start of the following calendar year. The common key for data from the various systems is the Singapore National Registration Identification (NRIC) number, which is a national identifier that is unique to each individual. All data are staged in eHINTS before being uploaded into the registry. There is no manual data entry. All data is kept securely within an approved access-controlled facility in SingHealth, in a manner compliant with local privacy and data protection laws.

\section{Diabetes Case Ascertainment Criteria}

Individuals with diabetes mellitus, aged 18 and above, are identified electronically from the SingHealth EMR data via pre-specified case ascertainment criteria, which are described in Table 1. The criteria include diagnosis codes, prescription records and laboratory test records. As the different healthcare settings in our healthcare cluster use different standardized diagnosis codes (ICD9/10 CM for inpatients, SNOMED-CT for outpatients in tertiary institutions, and SingHealth Polyclinic (SHP) Working Diagnosis Codes for primary care clinics), we manually defined the relevant diagnostic codes for each setting. Prescription and laboratory test records are standardized across the healthcare cluster, and so a common definition was used. The laboratory definition of diabetes has been standardized to include fasting plasma glucose, 2-hour plasma glucose (oral glucose tolerance test), and $\mathrm{HbAlc}$ results, aligning to local Ministry of Health guidelines. ${ }^{11} \mathrm{HbA} 1 \mathrm{c}$ has been used as a diagnostic test for diabetes with a cut point of $6.5 \%$ for diagnosing diabetes. ${ }^{12,21,22}$ However, HbA1c test is used only as a screening test for diabetes in Singapore. Individuals with an $\mathrm{HbA1c}$ of $6.0-6.9 \%$ are recommended to undergo a conventional fasting plasma glucose test or oral glucose tolerance test (OGTT) and would be diagnosed accordingly. Regardless, based on local epidemiologic data, HbA1c $7.0 \%$ is a reasonable
Table I Criteria Used for Case Ascertainment

\begin{tabular}{|c|c|c|}
\hline Criteria & Details & $\begin{array}{l}\text { Healthcare } \\
\text { Setting }\end{array}$ \\
\hline \multirow[t]{4}{*}{$\begin{array}{l}\text { Diagnosis } \\
\text { codes }\end{array}$} & $\begin{array}{l}\text { At least one primary or secondary } \\
\text { ICD-9-CMa diagnosis codes of } 250 \text {. } \\
x x, 362.0 x, 357.2 \text { or } 366.41\end{array}$ & $\begin{array}{l}\text { Inpatient } \\
\text { (pre-20/2) }\end{array}$ \\
\hline & $\begin{array}{l}\text { At least one primary or secondary } \\
\text { ICD-I0-CM }{ }^{\mathrm{a}} \text { diagnosis codes } \\
\text { starting with EIO, EII, EI } 3 \text { or EI4 }\end{array}$ & $\begin{array}{l}\text { Inpatient } \\
(2012 \\
\text { onwards) }\end{array}$ \\
\hline & $\begin{array}{l}\text { At least one SNOMED-CT diagnosis } \\
\text { code related to diabetes mellitus. } \\
\text { (List of codes in Supplementary } \\
\text { Table I) }\end{array}$ & Outpatient \\
\hline & $\begin{array}{l}\text { At least one SingHealth Polyclinic } \\
\text { (SHP) Working Diagnosis Codes for } \\
\text { diabetes mellitus. (List of codes in } \\
\text { Supplementary Table 2) }\end{array}$ & Outpatient \\
\hline $\begin{array}{l}\text { Prescription } \\
\text { records }\end{array}$ & $\begin{array}{l}\text { At least one glucose lowering drug } \\
\text { (GLD) prescribed. } \\
\text { GLDs include biguanides, } \\
\text { sulphonylureas, meglitinides, alpha- } \\
\text { glucosidase inhibitors, } \\
\text { thiazolidinediones, DPP-4 inhibitors, } \\
\text { SGLT2 inhibitors, GLP-I receptor } \\
\text { agonists, and insulin preparations. }\end{array}$ & $\begin{array}{l}\text { Inpatient and } \\
\text { outpatient }\end{array}$ \\
\hline $\begin{array}{l}\text { Laboratory } \\
\text { test records }\end{array}$ & $\begin{array}{l}\text { Any one of the following: } \\
\text { - Positive oral glucose tolerance test } \\
\text { (OGTT) } \\
>\text { fasting plasma glucose }>/=7.0 \\
\mathrm{mmol} / \mathrm{L} \text { and } / \text { or } \\
>\text { plasma glucose }>/=11.1 \mathrm{mmol} / \mathrm{L} \\
\text { at } 2 \text { hours } \\
-\mathrm{HbAlc}>/=7.0 \%\end{array}$ & $\begin{array}{l}\text { Inpatient and } \\
\text { outpatient }\end{array}$ \\
\hline
\end{tabular}

Note: ${ }^{a}$ ICD-10-CM replaced the ICD-9-CM in 2012.

level to "rule in" the diagnosis of diabetes without further testing. ${ }^{23}$ We have hence adopted the $7.0 \%$ cut point in our ascertainment criteria.

\section{Data Collected by the SingHealth Diabetes Registry}

For each individual, the SDR includes casemix variables and outcome variables. These were drawn from structured data fields within data source systems, and the definitions rigorously validated by domain experts within SingHealth. All extracted data undergo internal validation with inspection by data analysts and domain 
experts for anomalous values. Each individual also has process indicators examining the quality of diabetes management, which are derived from the above casemix and outcome variables.

We report in the results section the counts of individuals meeting diabetes case ascertainment criteria and summary statistics for casemix variables, as well as the summary of patients' meeting process indicators for each year. We also report the breakdown of $\mathrm{HbAlc}$ for each year, which is a major outcome measure for glycemic control.

Table 2 Details of Casemix Variables

\begin{tabular}{|c|c|}
\hline Category & Items \\
\hline \multirow{7}{*}{$\begin{array}{l}\text { Demographics and } \\
\text { lifestyle factors }\end{array}$} & Gender \\
\hline & Date of birth (used to calculate age) \\
\hline & Ethnicity (Chinese, Indian, Malay, Others) \\
\hline & Nationality \\
\hline & $\begin{array}{l}\text { Postal code, housing type (derived from } \\
\text { postal code) }\end{array}$ \\
\hline & Death date \\
\hline & Smoking status \\
\hline \multirow[t]{3}{*}{ Diagnosis Profile } & Diabetes type \\
\hline & Year of diagnosis \\
\hline & $\begin{array}{l}\text { Comorbidities (Hypertension, } \\
\text { hypercholesterolemia, established } \\
\text { cardiovascular disease }{ }^{\mathrm{a}} \text {, ischemic heart } \\
\text { disease, myocardial infarction, unstable angina, } \\
\text { coronary artery bypass graft, cardiac } \\
\text { catheterization, percutaneous coronary } \\
\text { intervention, peripheral artery disease, } \\
\text { cerebrovascular disease, ischemic stroke, } \\
\text { hemorrhagic stroke, transient ischemic attack, } \\
\text { angina pectoris, heart failure, atrial fibrillation) }\end{array}$ \\
\hline \multirow[t]{4}{*}{ Treatment factors } & Glucose lowering drugs (GLDs) \\
\hline & Anti-lipids \\
\hline & Anti-hypertensives \\
\hline & Anti-platelet \\
\hline \multirow[t]{3}{*}{ Anthropometric } & Height, weight, body mass index \\
\hline & $\begin{array}{l}\text { Systolic blood pressure, diastolic blood } \\
\text { pressure }\end{array}$ \\
\hline & Heart rate \\
\hline
\end{tabular}

Casemix variables include the following, and are detailed in Table 2:

1. Demographics and lifestyle factors

2. Diagnosis profile

3. Treatment factors

4. Anthropometric variables

Outcome variables include the following, and are detailed in Table 3:

1. Laboratory results relating to diabetes control and other comorbidities

2. Clinical episodes

3. Surgical procedures

4. Vaccinations

Process indicators include the following:

1. Body weight measurement

Table 3 Details of Outcome Variables

\begin{tabular}{|c|c|}
\hline Category & Items \\
\hline \multirow{8}{*}{$\begin{array}{l}\text { Laboratory } \\
\text { results }\end{array}$} & Glycemic indices: $\mathrm{HbAlc}$, Glucose \\
\hline & $\begin{array}{l}\text { Lipid panel (Total Cholesterol, HDL-cholesterol, } \\
\text { LDL-cholesterol, Triglycerides) }\end{array}$ \\
\hline & Liver indices (Serum $\mathrm{ALT}^{\mathrm{a}}, \mathrm{AST}^{\mathrm{b}}, \mathrm{GGT}^{\mathrm{c}}$, albumin) \\
\hline & Renal indices (Serum urea, creatinine, potassium) \\
\hline & $\begin{array}{l}\text { Urinalysis (Urine microalbumin/creatinine ratio, } \\
\text { urine protein/creatinine ratio) }\end{array}$ \\
\hline & $\begin{array}{l}\text { Hematological indices (Hemoglobin, white blood } \\
\text { cell count, platelet count) }\end{array}$ \\
\hline & Serum creatine kinase \\
\hline & Serum NT-proBNP \\
\hline \multirow{2}{*}{$\begin{array}{l}\text { Clinical } \\
\text { episodes }\end{array}$} & Hospital admissions, emergency department visits \\
\hline & Outpatient visits \\
\hline \multirow{5}{*}{$\begin{array}{l}\text { Surgical } \\
\text { procedures }\end{array}$} & Bariatric surgeries \\
\hline & Lower extremity amputation \\
\hline & Lower limb bypass and revascularization \\
\hline & Coronary artery bypass grafting \\
\hline & Percutaneous coronary interventions \\
\hline Vaccinations & Influenza vaccination \\
\hline
\end{tabular}


2. HbAlc test

3. Blood pressure measurement

4. LDL-cholesterol measurement

5. Eye assessment

6. Kidney assessment

7. Foot assessment

\section{Use of the SingHealth Diabetes Registry for Research}

We have implemented a formal workflow for requests of SDR data for research. All research requires ethical approval from the local Institutional Review Board, and concurrent review and approval by the SDR Disease Registry Committee. All data are anonymized before release to researchers, and researchers must sign a data use agreement that prohibits reidentification, and unauthorized data redistribution.

\section{Results}

The SDR presently stands at a total of 208,102 individuals. The breakdown of individuals identified by the ascertainment criteria of laboratory results, diagnosis codes, and medications are depicted in the form of a Venn diagram in Figure 1. The majority of individuals were observed to meet all three ascertainment criteria.

The individuals comprising the SDR were distributed among the various healthcare sites within our AMC. The healthcare site is defined as the hospital, specialty center, or primary care site that an individual

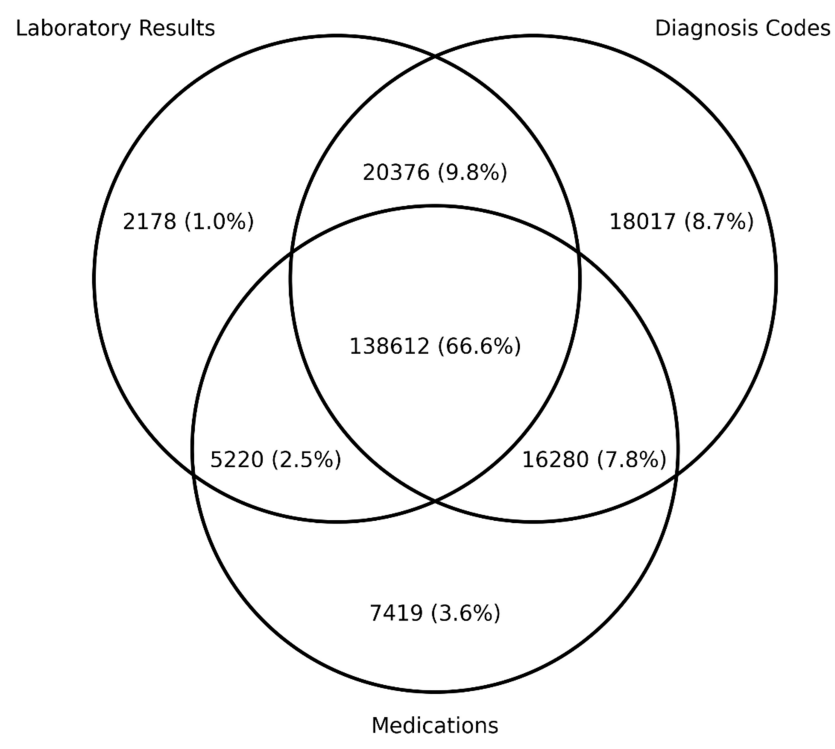

Figure I Venn diagram of individuals identified by ascertainment criteria.
Table 4 Total Counts of Individuals

\begin{tabular}{|l|l|l|}
\hline $\begin{array}{l}\text { Healthcare } \\
\text { Site } \\
\text { Acronym }\end{array}$ & Description & $\begin{array}{l}\text { Individuals } \\
\text { Contributed, } \\
\mathbf{n}(\%)\end{array}$ \\
\hline SHP & $\begin{array}{l}\text { SingHealth Polyclinics, comprising } \\
8 \text { primary healthcare clinics }\end{array}$ & $116,576(56.0)$ \\
\hline SGH & $\begin{array}{l}\text { Singapore General Hospital, } \\
\text { tertiary referral hospital }\end{array}$ & $25,317(12.2)$ \\
\hline CGH & $\begin{array}{l}\text { Changi General Hospital, tertiary } \\
\text { referral hospital }\end{array}$ & $14,501(7.0)$ \\
\hline SKH & $\begin{array}{l}\text { Sengkang General Hospital, } \\
\text { tertiary referral hospital }\end{array}$ & $3611(1.7)$ \\
\hline KKH & $\begin{array}{l}\text { KK Women's and Children's } \\
\text { Hospital, national pediatric and } \\
\text { women's hospital }\end{array}$ & $2260(1.1)$ \\
\hline NHCS & $\begin{array}{l}\text { National Heart Center } \\
\text { Singapore, national cardiac } \\
\text { referral center }\end{array}$ & $7672(3.7)$ \\
\hline NCCS & $\begin{array}{l}\text { National Cancer Center } \\
\text { Singapore, national cancer } \\
\text { referral center }\end{array}$ & $640(0.3)$ \\
\hline External & $\begin{array}{l}\text { Singapore National Eye Center, } \\
\text { national ophthalmology referral } \\
\text { center }\end{array}$ & $72(0)$ \\
\hline None of the above sites & $37,453(18.0)$ \\
\hline
\end{tabular}

had visited and received outpatient diabetes care defined by either a GLD prescription or having an $\mathrm{HbA} 1 \mathrm{c}$ test done. We adopted this practical definition to identify individuals who are followed up at our AMC for routine diabetes care. Individuals who met diabetes case ascertainment criteria but could not be associated with any healthcare site within the AMC are labelled as having an "external" healthcare site. These individuals likely received routine diabetes care outside of our AMC.

The total number of individuals contributed by each healthcare site, and a short description of each healthcare site, are enclosed in Table 4. 52.1\% were managed in a primary healthcare site, SingHealth Polyclinics (SHP), while $22.8 \%$ were managed in a tertiary healthcare site. The remaining individuals were deemed to be managed at external sites.

We report in Table 5 the casemix. Important demographic variables (age, sex, ethnicity, smoking status), diagnosis profile (diabetes type, diabetes medications), and selected major comorbidities are reported. 
Table 5 Summary Statistics of All Individuals

\begin{tabular}{|c|c|c|c|}
\hline \multicolumn{2}{|l|}{ Variable } & $\begin{array}{l}\text { Overall Cohort } \\
(N=208,102)\end{array}$ & $\begin{array}{l}\text { Cohort Excluding Patients Managed at } \\
\text { External Site }(n=\mid 70,649)\end{array}$ \\
\hline \multicolumn{2}{|c|}{ Mean age, years (SD) } & $65.8(13.7)$ & $65.9(13.5)$ \\
\hline Sex, n (\%) & Male & $106,657(51.3)$ & $88,154(51.7)$ \\
\hline \multirow[t]{4}{*}{ Ethnicity, n (\%) } & Chinese & $144,482(69.4)$ & $118,274(69.3)$ \\
\hline & Malay & $31,482(15.1)$ & $26,265(15.4)$ \\
\hline & Indian & $22,930(11.0)$ & $18,442(10.8)$ \\
\hline & Others & $9208(4.4)$ & $7668(4.5)$ \\
\hline \multicolumn{2}{|l|}{ Smoker, n (\%) } & $16,948(8.1)$ & $14,668(8.6)$ \\
\hline \multirow{3}{*}{$\begin{array}{l}\text { Diabetes type, } \\
\text { n (\%) }\end{array}$} & Type 2 & 206,59I (99.3) & $169,407(99.3)$ \\
\hline & Type I & $|27|(0.6)$ & $1009(0.6)$ \\
\hline & $\begin{array}{l}\text { Other (eg gestational, monogenic, drug- } \\
\text { induced, secondary diabetes) }\end{array}$ & $240(0.1)$ & $233(0.1)$ \\
\hline \multirow{3}{*}{$\begin{array}{l}\text { Diabetes } \\
\text { medications, n (\%) }\end{array}$} & Oral glucose-lowering medications only & $129,124(62.1)$ & $119,236(69.9)$ \\
\hline & Insulin preparations only & $7419(3.6)$ & $6624(3.9)$ \\
\hline & $\begin{array}{l}\text { Oral glucose-lowering medications and insulin } \\
\text { preparations }\end{array}$ & $35,067(16.9)$ & $32,819(19.2)$ \\
\hline \multicolumn{2}{|l|}{ Hypertension, n (\%) } & $175,059(84.1)$ & $150,443(88.2)$ \\
\hline \multicolumn{2}{|c|}{ Mean systolic blood pressure, mm Hg (SD) } & I33.7 (14.8) & I33.7 (14.6) \\
\hline \multicolumn{2}{|c|}{ Mean diastolic blood pressure, mm Hg (SD) } & $70.4(8.2)$ & $70.4(8.2)$ \\
\hline \multicolumn{2}{|c|}{ Hyperlipidemia, n (\%) } & $179,434(86.2)$ & $157,862(92.5)$ \\
\hline \multicolumn{2}{|c|}{ Established cardiovascular disease, $\mathrm{n}(\%)$} & $70,952(34.1)$ & $61,680(36.1)$ \\
\hline
\end{tabular}

For individuals who were managed within the AMC, we document below the counts and percentages of those meeting relevant process indicators in each year in Table 6 .

Finally, we report in Figure 2 the distribution of mean $\mathrm{HbAlc}$ of the individuals managed within the AMC for each year. The mean $\mathrm{HbAlc}$ values are categorised into ranges reflecting differing levels of glycemic control. For the most recent year (2019), 64,296 individuals $(52.7 \%)$ met the target of mean $\mathrm{HbA} 1 \mathrm{c}<7 \%$ ( $53 \mathrm{mmol} / \mathrm{mol})$, while 34,031 individuals $(27.9 \%$ ) had a mean HbA1c from $7-8 \%$ (53-64 mmol/mol), and 23,747 (19.5\%) had a mean $\mathrm{HbAlc}>8 \%$ (64 $\mathrm{mmol} / \mathrm{mol})$.

\section{Discussion}

Our registry relies on large-scale data collection via automated retrieval from EMR source databases and clinical databases. The main advantage of this approach is that manual data entry is not required, thus eliminating the need for inputs from healthcare staff beyond usual clinical care and reducing the burden of database maintenance. Minimal direct handling of patient records also decreases the risk of data privacy and security breaches. We are also able to achieve cross-disciplinary integration of data, for a more comprehensive view of the various facets of diabetes comorbidity and care.

However, we recognize that an EMR-based approach does have limitations. ${ }^{24}$ Records external to the electronic data systems drawn on cannot be directly captured, for example, laboratory results and prescriptions done at a different healthcare cluster. Furthermore, despite extensive internal validation of the data fields used in defining the registry, we acknowledge that it may be difficult to determine the accuracy of some data (eg comorbidities) without further external validation. Additional relevant information may also reside in unstructured free text 
Table 6 Individuals Meeting Process Indicators

\begin{tabular}{|c|c|c|c|c|c|c|c|}
\hline Process Indicator & 2013 & 2014 & 2015 & 2016 & 2017 & 2018 & 2019 \\
\hline$\geq 2$ Body weight measurements & I4, I73 (I7.4) & $53,404(60.0)$ & $61,271(65.1)$ & $67,892(68.8)$ & $80,331(82.0)$ & $98,263(83.7)$ & $103,193(83.5)$ \\
\hline$\geq 2 \mathrm{HbAlc}$ tests & $68,877(84.7)$ & $72,320(81.3)$ & $77,508(82.3)$ & $82,324(83.4)$ & $84,460(86.2)$ & $96,288(82.0)$ & $100,090(81.0)$ \\
\hline$\geq 2$ blood pressure measurements & $69,49 \mid(85.5)$ & $66,035(74.2)$ & $75,089(79.7)$ & $79,086(80.1)$ & $89,114(90.9)$ & $109,443(93.2)$ & $115,218(93.2)$ \\
\hline$\geq$ I LDL-c measurements & $71,229(87.6)$ & $75,285(84.6)$ & $80,960(86.0)$ & $85,882(87.0)$ & $86,285(88.1)$ & $100,703(85.8)$ & $105,146(85.1)$ \\
\hline$\geq$ I Eye assessment ${ }^{\mathrm{a}}$ & $50,455(62.1)$ & $57,056(64.1)$ & $60,853(64.6)$ & $65,744(66.6)$ & $65,465(66.8)$ & $70,671(60.2)$ & $74,944(60.6)$ \\
\hline$\geq$ I Kidney assessment ${ }^{\mathrm{b}}$ & $74,633(91.8)$ & $80,245(90.2)$ & $86,089(91.4)$ & $91,131(92.3)$ & $91,605(93.5)$ & $109,720(93.5)$ & II $5,969(93.8)$ \\
\hline$\geq$ I Foot assessment ${ }^{c}$ & $47,182(58.0)$ & $48,654(54.7)$ & $53,562(56.9)$ & $59,822(60.6)$ & $58,275(59.5)$ & $63,601 \quad(54.2)$ & $62,679(50.7)$ \\
\hline
\end{tabular}

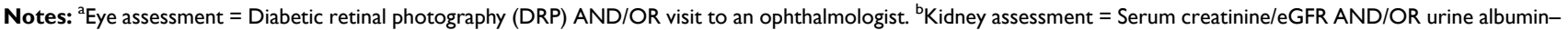
creatinine ratio (UACR) AND/OR urine protein-creatinine ratio (UPCR). ${ }^{\circ}$ Foot assessment $=$ Diabetic foot screen (DFS) AND/OR visit to a podiatrist.

records, which are challenging to parse and were not included in the current registry. These factors can cause unmeasured bias within the SDR, as with any other EMR-based registry. These potential limitations must be recognized by future studies. However, there are no other practicable ways to achieve such data collection at scale, and the large scale of data in itself can allow valid conclusions even if there are small sources of bias.
We believe that our ascertainment of patients with diabetes has high validity, given the general concordance between the three broad categories of ascertainment criteria (laboratory results, diagnosis codes, and medications). 66.6\% of patients met all three criteria. However, we do note that small proportions of patients could only be identified with a single ascertainment criterion (8.7\% diagnosis code only, $3.6 \%$ medications only, and $1.0 \%$ laboratory results only). It

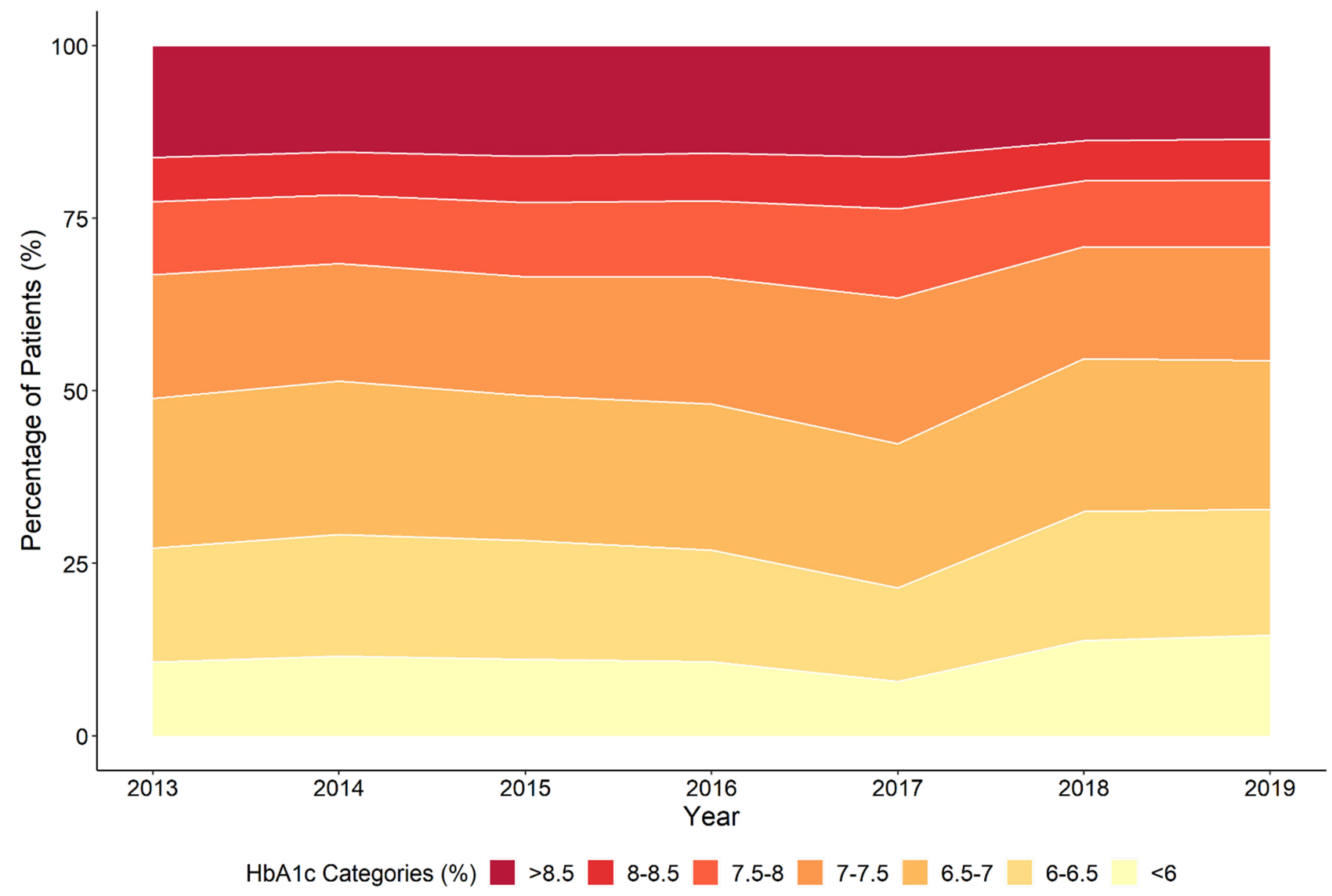

Figure 2 Distribution of mean $\mathrm{HbAlc}$ for individuals in the SDR in each year. 
is thus important to consider all aspects of the digital footprint of individuals with diabetes, and other diabetes registry owners should take this into account during registry construction to avoid under-identification of their diabetes cohorts.

Our casemix is broadly reflective of the national gender and ethnic distributions. ${ }^{25}$ Individuals in this cohort are older, with a mean age of $65.8 \pm 13.7$ years. The overwhelming majority (>99\%) have type 2 diabetes, and many have comorbid hypertension, hyperlipidemia, and established cardiovascular disease. This is congruent with recent literature on multimorbidity in Singapore, ${ }^{26}$ which shows that diabetes has a high co-occurrence rate with hypertension, hyperlipidemia, and cardiovascular disease. An important limitation to the analysis of casemix is that information on the socioeconomic status of individuals in the SDR is not directly available. This should be taken into consideration by future researchers, given that multimorbidity in Singapore has been shown to correlate with lower socioeconomic status. Additionally, although the vast majority of healthcare in Singapore is consumed within the public sector, it is possible that individuals of a higher socioeconomic status within the geographic catchment area have chosen privately managed healthcare. This is a potential minor contributor to selection bias in our casemix.

We note that the NHGDR, ${ }^{9}$ another local diabetes registry last described in 2008, also described frequent co-occurrence of diabetes with hypertension, hyperlipidemia, and cardiovascular disease, albeit in only $20-30 \%$ of individuals included. This stands in contrast to the SDR, which has $30-90 \%$ of patients having co-occurring cardiovascular morbidities. This may reflect better capture of co-morbidities due to widespread digitization over the past 10 years, with a complete transition to EMR within the SingHealth AMC. The patients in the SDR are also older, reflecting demographic transitions that have occurred during this period, and would also be expected to have a higher burden of comorbid disease.

Overall, the majority of the individuals in the SDR have met the process indicators. There have been sustained improvements in indicators, such as body weight measurement, blood pressure measurement, and biochemical measurements (eg HbA1c, LDL-cholesterol, estimated glomerular filtration rate, albuminuria). However, the current rates of eye and foot assessments are areas in which the AMC is aiming for improvement. Likewise, the distribution of HbAlc values has shown gradual improvement through the years, but almost $50 \%$ of individuals have not achieved a mean HbAlc of $<7 \%$ (53 $\mathrm{mmol} / \mathrm{mol}$ ). While individuals in our cohort are older and have more liberal HbA1c targets, approximately $20 \%$ still have a mean HbAlc of $>8 \%(64 \mathrm{mmol} / \mathrm{mol})$. This is another area of improvement for the AMC.

\section{Conclusion}

The SDR is a large-scale and comprehensive diabetes registry that incorporates EMR data across the primary and hospital-based care continuum, in a major AMC in Singapore. The current cohort within the registry is representative of the national ethnic and gender distributions. The SDR has identified areas of improvement in the diabetes process and outcomes for improvement. It is hoped the SDR will continue to support quality assessment and improvements in diabetes care.

\section{Acknowledgments}

We acknowledge the support of the Health Service Research Unit (Singapore General Hospital), the Singapore Cardiac Data Bank (National Heart Center Singapore) and the Singapore Integrated Diabetic Retinopathy Program (Singapore National Eye Center).

\section{Funding}

The establishment of the SDR was supported by the SingHealth Duke-NUS Medicine Academic Clinical Programme Clinical Innovation Support Programme Grant.

\section{Disclosure}

The authors report no conflicts of interest in this work.

\section{References}

1. Disease burden statistics, Ministry of Health Singapore. Available from: https://www.moh.gov.sg/resources-statistics/singapore-healthfacts/disease-burden. Accessed October 26, 2020.

2. Global burden of disease report 2017 (Singapore). Available from: http://www.healthdata.org/sites/default/files/files/policy_report/2019/ GBD_2017_Singapore_Report.pdf. Accessed November 3, 2020.

3. Hayward RA, Hofer TP, Kerr EA, Krein SL. Quality improvement initiatives: issues in moving from diabetes guidelines to policy. Diabetes Care. 2004;27(Suppl 2):B54-B60. doi:10.2337/diacare.27. suppl_2.B54

4. Dean HJ, Tu JV. Clinical databases are a vital component of quality improvement initiatives in diabetes care. Can J Diabetes. 2007;31 (4):350-351. doi:10.1016/s1499-2671(07)14002-8

5. Hermans MP, Elisaf M, Michel G, et al. Benchmarking is associated with improved quality of care in type 2 diabetes: the OPTIMISE randomized, controlled trial. Diabetes Care. 2013;36(11):3388-3395. doi: $10.2337 / \mathrm{dc} 12-1853$ 
6. O'Connor PJ, Bodkin NL, Fradkin J, et al. Diabetes performance measures: current status and future directions. Diabetes Care. 2011;34(7):1651-1659. doi:10.2337/dc11-0735

7. Diabetes reference guide, international consortium for health outcomes measurement. Available from: https://ichom.org/files/medi cal-conditions/diabetes-in-adults/dia-reference-guide.pdf. Accessed October 26, 2020.

8. Bak JCG, Serné EH, Kramer MHH, Nieuwdorp M, Verheugt CL. National diabetes registries: do they make a difference? Acta Diabetol. 2020;57(1):1-12. doi:10.1007/s00592-019-01369-8

9. Heng BH, Sun Y, Cheah JT, Jong M. The Singapore national healthcare group diabetes registry-descriptive epidemiology of type 2 diabetes mellitus. Ann Acad Med Singapore. 2010;39(5).

10. War on diabetes report, Ministry of Health Singapore. Available from: https:/www-moh-gov-sg-admin.cwp.sg/docs/librariesprovider5/war-ondiabetes/wod_public_report.pdf. Accessed November 10, 2020.

11. Release of new screening test review committee guidelines, including changes to diabetes mellitus, lipid disorders, and cervical cancer screening, Ministry of Health Singapore. Available from: https:// www.moh.gov.sg/docs/librariesprovider5/licensing-terms-and-condi tions/moh-cir-no-08_2019_6mar19_screening.pdf. Accessed October 26, 2020.

12. World Health Organization. Use of glycated haemoglobin (HbA1c) in the diagnosis of diabetes mellitus. Available from: https://www.who.int/dia betes/publications/report-hba1c_2011.pdf. Accessed January 5, 2021.

13. Buse JB, Wexler DJ, Tsapas A, et al. 2019 Update to: management of hyperglycemia in type 2 diabetes, 2018. A consensus report by the American Diabetes Association (ADA) and the European Association for the Study of Diabetes (EASD). Diabetes Care. 2020;43 (2):487-493. doi:10.2337/dci19-0066

14. SingHealth key figures and statistics; 2020. Available from: https:// www.singhealth.com.sg/about-singhealth/newsroom/Documents/ SingHealth\%20Duke-NUS\%20AR1920-OVERVIEW_final.pdf. Accessed October 30, 2020.

15. Personal data protection act 2012 - Singapore statutes online. Available from: https://sso.agc.gov.sg/Act/PDPA2012. Accessed November 10, 2020.

16. Human biomedical research act 2015 - Singapore statutes online. Available from: https://sso.agc.gov.sg/Act/HBRA2015. Accessed November 10, 2020
17. World Medical Association. World medical association declaration of Helsinki: ethical principles for medical research involving human subjects. JAMA. 2013;310(20):2191-2194. doi:10.1001/jama.2013.28 1053

18. Yeo KK, Ong H-Y, Chua T, et al. Building a longitudinal national integrated cardiovascular database - lessons learnt from SingCLOUD -. Circ Rep. 2020;2(1):33-43. doi:10.1253/circrep.cr19-0106

19. Loh JP, Tan -L-L, Zheng H, et al. First medical contact-to-device time and heart failure outcomes among patients undergoing primary percutaneous coronary intervention. Circ Cardiovasc Qual Outcomes. 2018;11(8):e004699. doi:10.1161/CIRCOUTCOMES.118.004699

20. Nguyen HV, Tan GSW, Tapp RJ, et al. Cost-effectiveness of a national telemedicine diabetic retinopathy screening program in Singapore. Ophthalmology. 2016;123(12):2571-2580. doi:10.1016/j. ophtha.2016.08.021

21. Mellitus D. Diagnosis and classification of diabetes mellitus. Diabetes Care. 2012;35(Suppl1). doi:10.2337/dc12-s064

22. The International Expert Committee*. International expert committee report on the role of the $\mathrm{A} 1 \mathrm{C}$ assay in the diagnosis of diabetes. Diabetes Care. 2009;32(7):1327. doi:10.2337/dc09-9033

23. Lim W-Y, Ma S, Heng D, Shyong Tai E, Khoo CM, Loh TP. Screening for diabetes with HbAlc: test performance of HbAlc compared to fasting plasma glucose among Chinese, Malay and Indian community residents in Singapore. Sci Rep. 2018;8(1):1-9. doi:10.1038/s41598-018-29998-Z

24. Hayrinen K, Saranto K, Nykanen P. Definition, structure, content, use and impacts of electronic health records: a review of the research literature. Int J Med Inform. 2008;77(5):291-304. doi:10.1016/j. ijmedinf.2007.09.001

25. What are the racial proportions among Singapore citizens? Available from: https://www.gov.sg/article/what-are-the-racial-proportionsamong-singapore-citizens. Accessed October 28, 2020.

26. Low LL, Kwan YH, Ko MSM, et al. Epidemiologic characteristics of multimorbidity and sociodemographic factors associated with multimorbidity in a rapidly aging Asian country. JAMA Netw Open. 2019;2(11):e1915245. doi:10.1001/jamanetworkopen.2019.15245
Clinical Epidemiology

\section{Publish your work in this journal}

Clinical Epidemiology is an international, peer-reviewed, open access, online journal focusing on disease and drug epidemiology, identification of risk factors and screening procedures to develop optimal preventative initiatives and programs. Specific topics include: diagnosis, prognosis, treatment, screening, prevention, risk factor modification,

Submit your manuscript here: https://www.dovepress.com/clinical-epidemiology-journal systematic reviews, risk \& safety of medical interventions, epidemiology \& biostatistical methods, and evaluation of guidelines, translational medicine, health policies \& economic evaluations. The manuscript management system is completely online and includes a very quick and fair peer-review system, which is all easy to use. 